\title{
Adsorção de óleos lubrificantes em casca de arroz
}

O uso de óleos lubrificantes, apesar de ter o benefício de aumentar a eficiência de equipamentos e sua vida útil, causa prejuízos ambientais pela geração de resíduos contaminados e poluição de corpos hídricos. O tratamento destes resíduos é fundamental para garantir a sanidade do meio ambiente. Em vista disso, uma solução de baixo custo é o aproveitamento de resíduos, como a casca de arroz, para utilização como meio adsorvente. A casca de arroz foi utilizada sem prétratamento em tempos de reação de cinco, quinze e trinta minutos, uma, duas e quatro horas. Os experimentos foram feitos em bateladas, com relações de adsorbato/adsorvente de 5,0 mL.g-1 e de 2,0 mL.g-1. Com base nos resultados foram estabelecidas as curvas de adsorção do sistema. Foi observado que a adsorção do óleo na casca de arroz ocorre de forma rápida, sendo adsorvidos entre 65 e $70 \%$ da capacidade total do adsorvente nos primeiros cinco minutos de contato. 0 equilíbrio dos processos de adsorção/dessorção mostrou que a capacidade máxima de retenção de óleo na casca de arroz foi de 1,91 g.g-1 (2,20 mL.g-1). A remoção de óleo na proporção de 2,0 mL.g-1 foi de até 94\%, reduzindo a concentração de óleo no efluente de 86,7 g.L-1 para 5,4 g.L-1.

Palavras-chave: Adsorvente; Resíduos; Teor de Graxas; Efluente.

\section{Adsorption of rice husk lubricating oils}

The use of lubricating oils, despite having the benefit of increasing equipment efficiency and service life, cause environmental damage by the generation of contaminated waste and pollution of water bodies. The treatment of these wastes is essential to guarantee the sanity of the environment. As a result, a low cost solution is the use of residues, such as rice husks, for use as an adsorbent medium. The rice husk was used without pre-treatment in reaction times of five, fifteen and thirty minutes, one, two and four hours. The experiments were done in batch, with adsorbate/adsorbent ratios of $5.0 \mathrm{~mL} . \mathrm{g}-1 \mathrm{and} 2.0 \mathrm{~mL} . \mathrm{g}-1$. Based on the results the adsorption curves of the system were established. It was observed that the adsorption of the oil in the rice husk occurs rapidly, adsorbing between 65 and $70 \%$ of the total capacity in the first five minutes of contact. The equilibrium of the adsorption/desorption processes showed that the maximum oil retention capacity in the rice hull was $1.91 \mathrm{~g} . \mathrm{g}-1(2.20 \mathrm{~mL} . \mathrm{g}-1)$. The oil removal at the rate of $2.0 \mathrm{~mL} . \mathrm{g}-1$ was up to $94 \%$, reducing the effluent oil concentration from $86.7 \mathrm{~g}$.L1 to 5.4 g.L-1.

Keywords: Adsorbent; Residues; Grease Content; Effluent.

Topic: Uso de Recursos Naturais

Reviewed anonymously in the process of blind peer.
Received: $10 / 06 / 2018$

Approved: $24 / 07 / 2018$
Louise Hoss

Universidade Federal de Pelotas, Brasil http://lattes.cnpq.br/7104580814200147 hosslouise@gmail.com

\section{Larissa Loebens (iD)}

Universidade Federal de Pelotas, Brasil http://orcid.org/0000-0002-4270-4183

http://lattes.cnpq.br/2881245126256479

laryloebens2012@gmail.com

Luiz Alfredo Bohlke Neto (iD)

Universidade Federal de Pelotas, Brasil

http://lattes.cnpq.br/2870748385166847

http://orcid.org/0000-0002-7967-3130

luizbohlke@hotmail.com

\author{
Maurizio Silveira Quadro (iD) \\ Universidade Federal de Pelotas, Brasil \\ http://lattes.cnpq.br/1749935262841216 \\ http://orcid.org/0000-0001-8236-7479 \\ mausq@hotmail.com \\ Robson Andreazza (iD \\ Universidade Federal de Pelotas, Brasil \\ http://lattes.cnpq.br/5706766977817721 \\ http://orcid.org/0000-0001-9211-9903 \\ robsonandreazza@yahoo.com.br \\ Gizele Ingrid Gadotti (D) \\ Universidade Federal de Pelotas, Brasil \\ http://lattes.cnpq.br/4110765012494684 \\ http://orcid.org/0000-0001-9545-6577 \\ gizeleingrid@gmail.com
}

\section{Referencing this:}

HOSS, L.; LOEBENS, L.; BOHLKE NETO, L. A.; QUADRO, M. S.; ANDREAZZA, R.; GADOTTI, G. I.. Adsorção de óleos lubrificantes em casca de arroz. Revista Ibero Americana de Ciências Ambientais, v.9, n.5, p.22-28, 2018. DOI: http://doi.org/10.6008/CBPC21796858.2018.005.0003 


\section{INTRODUÇÃO}

Apesar de representar um notável avanço tecnológico na atualidade, o desenvolvimento das máquinas e meios de transporte automotivos trouxe consigo a necessidade do uso de lubrificantes em seus componentes, para seu pleno funcionamento. $\mathrm{O}$ uso destes óleos e lubrificantes pode ocasionar a degradação do meio ambiente, visto que produzem resíduos classificados como perigosos pela NBR 10.004, e pelas dificuldades no reaproveitamento do óleo usado.

Ademais, estes resíduos podem estar presentes em efluentes de locais que trabalham com estes produtos, como postos de combustíveis, oficinas mecânicas, postos de autolavagem, estacionamentos, frotistas, transportadoras e instalações industriais em geral, e normalmente são gerados da lavagem de veículos e peças, de acidentes como derramamentos (GMP, 2005; NETO, 2017).

É proibido por lei dispor efluentes contaminados por óleos no solo, em corpos hídricos ou de maneira que causem contaminação atmosférica (CONAMA, 2005). Além disso, existe o risco de acidentes em seu manejo e acondicionamento, como derramamentos e vazamentos, e também o descuido e insipiência à legislação no que se refere ao descarte de seus resíduos e efluentes (NETO, 2017).

Os efluentes contendo óleos e graxas geram diversos problemas ambientais quando lançados em corpos hídricos sem tratamento, como a formação de filme sobre a superfície da água, o que dificulta as trocas gasosas entre a atmosfera e o meio líquido, e o aumento da DQO e DBO pela decomposição química e bioquímica dos óleos e graxas (MAGALHÃES et al., 2013). À vista disso, o tratamento dos efluentes contaminados por óleos é substancial para garantir a sanidade do meio ambiente. Usualmente são utilizados filtros e materiais adsorventes, no entanto o alto custo destes tratamentos torna-se um empecilho (NETO, 2017).

A utilização de materiais alternativos, de baixo custo e alta disponibilidade surge como uma solução para este problema, podendo ser utilizados materiais que normalmente são vistos como resíduos. Como exemplos, podem ser usadas algas, bagaço de cana de açúcar e palha de arroz (MOREIRA, 2010), além de matérias de origem animal, como a quitosana (SIGNINI et al., 2010; HEMALATHA et al., 2011; DAI et al., 2012). O objetivo deste trabalho foi avaliar a capacidade e eficiência de adsorção de óleos lubrificantes na casca de arroz sem tratamento prévio, como alternativa no tratamento de efluentes contaminados por óleos lubrificantes de origem mineral.

\section{MATERIAIS E MÉTODOS}

Os experimentos foram conduzidos no campus Cotada da Universidade Federal de Pelotas (UFPel) no Laboratório de Análise de Águas e Efluentes, no período de janeiro a agosto de 2017. Para realização do experimento foi utilizado o óleo lubrificante de base mineral, multiviscoso para motores a gasolina, etanol e GNV, de viscosidade no padrão SAE de 20 W50 da marca Lubri Motor's's, série Golden. Foi utilizado como material adsorvente a casca de arroz in natura, fornecida por indústrias da região. Para caracterização da casca de arroz foram determinados umidade e óleos e graxas conforme metodologia da American Society for 
Testing and Materials (ASTM) e Standard Methods for Examination of Water and Wastewater (APHA, 2005), respectivamente. Todas as análises aqui descritas foram realizadas em triplicata. A Tabela 1 apresenta os resultados da caracterização da casca.

Tabela 1: Caracterização da casca de arroz proveniente de uma indústria da região de Pelotas, RS. 2017.

\begin{tabular}{|l|l|}
\hline Parâmetro & Valor \\
\hline Umidade $(\%)$ & $14,79 \pm 0,53$ \\
\hline Teor de Óleos e Graxas $(\mathrm{mg} / \mathrm{g})$ & $1,53 \pm 0,18$ \\
\hline Densidade aparente $\left(\mathrm{kg} \cdot \mathrm{m}^{-3}\right)^{1}$ & 377,24 \\
\hline Porosidade $(\%)^{1}$ & 64,20 \\
\hline
\end{tabular}

Os ensaios de adsorção foram conduzidos em batelada. Foi utilizada uma diluição de $5 \mathrm{~mL}$ de óleo lubrificante em $50 \mathrm{~mL}$ de água destilada (1:10). A temperatura foi mantida em 20 으 e o pH neutro em todos ensaios. O Óleo Lubrificante Mineral (OLM) foi pesado a cada ensaio após ser colocado na água destilada para avaliar o valor de sua densidade, que foi estimada em $0,8670 \mathrm{~g} \cdot \mathrm{mL}^{-1}$, em conformidade com o fornecido pelo fabricante. Portanto o óleo total adicionado a cada batelada foi de 4,335 g e sua concentração na solução foi de $78,82 \mathrm{~g} \cdot \mathrm{L}^{-1}$.

Foram utilizadas as relações de adsorbato/adsorvente $(P)$ nas proporções de 5,0 mL.g ${ }^{-1}$ (Tratamento 1) e de $2,0 \mathrm{~mL} \cdot \mathrm{g}^{-1}$ (Tratamento 2). No tratamento 1 foi adicionando $1 \mathrm{~g}$ de casca de arroz à cada batelada e no Tratamento 2 foi adicionando $2,5 \mathrm{~g}$ à cada batelada. Foram realizadas bateladas com tempos de reação de $5 \mathrm{~min}, 15 \mathrm{~min}, 30 \mathrm{~min}, 1 \mathrm{~h}, 2 \mathrm{~h}$ e $4 \mathrm{~h}$ em agitação constante. Os recipientes foram selados com papel filme para diminuir a interferência do ar atmosférico, conforme sugerido por Nascimento et al. (2014). Todos os ensaios foram realizados em triplicatas.

Após cada batelada a mistura (água contaminada + adsorvente) foi colocada em uma peneira sobre funil com papel filtro, para extração do adsorvente. O material foi filtrado por 15 minutos e lavado com água destilada para remoção do excesso de óleo não adsorvido à biomassa. $\mathrm{O}$ adsorvente foi separado e imediatamente colocado em um cartucho celulósico para o processo de extração do óleo adsorvido na casca, através do aparelho Soxhlet, em processo adaptado do Standard Methods (APHA, 1999), seção 5520 D. Para extração do óleo foi utilizado o reagente n-hexano PA, em uma operação de 20 ciclos por hora durante 4 horas.

Para a análise estatística foi montado um experimento fatorial com um fator qualitativo e um quantitativo. $O$ fator qualitativo possuía dois níveis de proporção óleo/casca (tratamento 1 e 2). 0 fator quantitativo possuía 6 níveis, que foram os tempos de reação utilizados. 0 experimento foi conduzido em delineamento totalmente casualizado, com três repetições por tratamento. A análise estatística dos dados foi feita com o Software de Análise Estatística (WINSTAT) utilizando-se análise de variância (teste F), e as diferenças significativas foram determinadas pelo teste de comparações múltiplas de Tukey.

\section{RESULTADOS E DISCUSSÃO}

Foram observados umidade na casca de arroz de 14,79\% \pm 0,53\% (Tabela 2). Estes valores são relativamente altos quando comparado aos encontrados por Zhang (2012) e Penha (2016), respectivamente 
de 4,72\% a 6,35\%. Esta diferença de resultado pode ser advinda das condições de armazenamento e diferenças climáticas pertinentes à região, pois a mesma possui característica de alta umidade relativa e o material é higroscópico.

Foram determinados teores de $1,53 \mathrm{mg} \cdot \mathrm{g}^{-1}$ de óleos e graxas nas amostras de casca de arroz utilizadas. Este teor foi considerado relativamente baixo, não interferindo de forma significativa na remoção do óleo lubrificante, pois é um valor irrelevante quando comparado ao adsorvido pela casca nos processos de tratamento. É de conhecimento que o farelo de arroz possui alta concentração de ácidos graxos. Desta forma, não foi verificada a necessidade de remoção do mesmo antes do uso da biomassa nos ensaios. O que se faz interessante para não haver a necessidade de processamento industrial da casca e com isso o aumento do custo, descaracterizando o seu propósito.

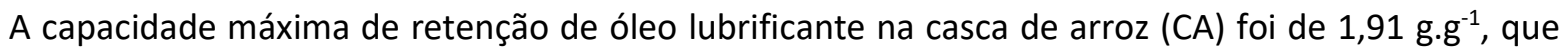
ocorreu no tempo de 4 horas na proporção $5,0 \mathrm{~mL}$ de óleo lubrificante mineral por grama de casca (Tratamento 1). Os resultados encontrados no Tratamento 1, quando utilizados um grama de casca de arroz na solução (5,0 mL de óleo lubrificante mineral por grama de casca de arroz) são mostrados na Tabela 2 . Para a construção dos dados foram utilizadas as médias dos valores obtidos nos ensaios de absorção. A adsorção do óleo às camadas mais superficiais da casca é uma reação extremamente rápida por conta das fibras lignocelulósicas de sua composição. Em razão disto, uma adsorção de 1,54 g ocorreu logo aos 5 min de reação, atingindo $80 \%$ da capacidade total de adsorção do material.

Tabela 2: Adsorção de óleo lubrificante mineral (OLM) para o tratamento de 5,0 mL.g $\mathrm{g}^{-1}$ de adsorbato/adsorvente.

\begin{tabular}{|l|l|l|l|}
\hline Tempo de contato (h) & Óleo adsorvido (g.g-1) & Óleo removido (\%) & Capacidade de adsorção (\%) \\
\hline 0,08 & 1,54 & 35,51 & 80,61 \\
\hline 0,25 & 1,70 & 39,18 & 88,94 \\
\hline 0,50 & 1,73 & 39,92 & 90,60 \\
\hline 1,00 & 1,80 & 41,45 & 94,10 \\
\hline 2,00 & 1,89 & 43,62 & 99,01 \\
\hline 4,00 & 1,91 & 44,05 & 100,00 \\
\hline
\end{tabular}

A baixa diferença entre o total adsorvido após 2 h e 4 h de contato mostra que o valor de 1,91 g é próximo do ponto de equilíbrio de adsorção entre a casca de arroz e o óleo lubrificante mineral. O desvio padrão médio dos resultados de adsorção foi de 0,05 g considerados baixos e adequados. Os resultados encontrados para as quantidades de óleo lubrificante mineral adsorvidas na casca de arroz são relativamente baixos quando comparados a estudos encontrados na literatura. Quando comparado a estudos de sorção de óleos em biomassa, percebe-se que diversos trabalhos (ANNUNCIADO et al., 2005; RIBEIRO et al., 2000) apresentam resultados que expressam quantidades de sorvato como água mais óleo, e não apenas o óleo em si. Ou ainda, realizam testes a seco, sendo a amostra colocada em óleo puro, sem a presença de água. Muitos destes trabalhos podem servir como comparativo das capacidades de adsorção das biomassas em diferentes condições de tratamento e à exposição de diferentes adsorbatos.

A média dos resultados obtidos nos ensaios com $2,5 \mathrm{~g}$ de CA na solução $(2,0 \mathrm{~mL}$ de óleo lubrificante mineral por grama de casca de arroz) são expressos na Tabela 3. Pode-se observar que houve uma remoção 
muito alta do óleo lubrificante mineral logo aos cinco minutos do experimento ( $78 \%$ do total). Nesta situação, o efluente final obteve um teor de óleos e graxas (TOG) de 28 g.L.-1.

Tabela 3: Adsorção de óleo lubrificante mineral (OLM) para o tratamento de 2,0 mL.g $\mathrm{g}^{-1}$ de adsorbato/adsorvente.

\begin{tabular}{|l|l|l|l|l|}
\hline Tempo de contato $(\mathrm{h})$ & Óleo adsorvido $(\mathrm{g})$ & Óleo adsorvido por grama (g/g) & Óleo removido (\%) & Capacidade de adsorção (\%) \\
\hline 0,08 & 3,39 & 1,35 & 78,09 & 83,28 \\
\hline 0,25 & 3,52 & 1,41 & 81,28 & 86,69 \\
\hline 0,50 & 3,64 & 1,46 & 84,06 & 89,64 \\
\hline 1,00 & 1,52 & 87,76 & 93,60 \\
\hline 2,00 & 3,80 & 1,55 & 89,58 & 95,53 \\
\hline 4,00 & 3,88 & 1,63 & 93,77 & 100,00 \\
\hline
\end{tabular}

Neste tratamento o ponto de saturação (equilíbrio) entre adsorvente e adsorbato não é tão facilmente deduzido por haver uma maior diferença entre os dois últimos tempos de reação ( 2 e $4 \mathrm{~h}$ de contato). A situação de equilíbrio pode não ter sido alcançada porque a concentração de óleo lubrificante mineral - OLM disponível para adsorção ao longo do experimento se tornou muito baixa na solução, desacelerando o processo. A remoção de óleo lubrificante mineral ao fim do ensaio de $4 \mathrm{~h}$ foi de até $94 \%$, reduzindo a concentração de óleo no efluente de $86,7 \mathrm{~g} \cdot \mathrm{L}^{-1}$ para $5,4 \mathrm{~g} \cdot \mathrm{L}^{-1}$, uma diferença considerável ao encontrado no ensaio de $2 \mathrm{~h}$, com remoção de $90 \%$ do óleo, quando considerado a obtenção do ponto de equilíbrio deste sistema.

Esta proporção adsorbato/adsorvente mostrou uma menor adsorção de óleo lubrificante mineral por grama de casca de arroz ao longo do tempo, entre $12 \%$ e $18 \%$, quando comparada à proporção $5,0 \mathrm{~mL}^{-1}$ nos mesmos períodos. Novamente, esta diferença pode ser explicada pela menor disponibilidade de óleo lubrificante mineral na solução ou ainda pela formação de aglomerados de casca de arroz, diminuindo o acesso de algumas porções da biomassa ao óleo lubrificante mineral. $\mathrm{O}$ desvio padrão médio dos resultados de adsorção foi de 0,03 g considerados baixos e adequados e menores que o tratamento anterior.

As curvas de adsorção para os dois tratamentos são mostradas nas Figuras 1 e 2 abaixo. Pode ser observado que o tratamento com $5,0 \mathrm{~mL}(\mathrm{OLM}) / \mathrm{g}_{(\mathrm{CA})}$ apresentou uma maior velocidade de reação, quando comparado ao tratamento com $2,0 \mathrm{~mL}(\mathrm{OLM}) / \mathrm{g}_{(\mathrm{CA})}$, pois alcançou um valor muito próximo do equilíbrio com 2 $\mathrm{h}$ de tratamento.

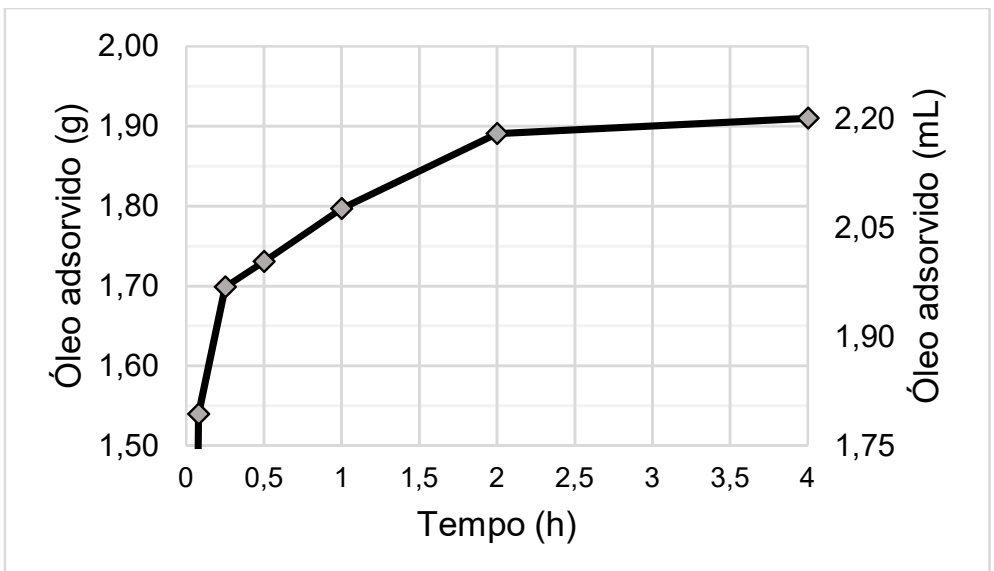

Figura 1: Adsorção de óleo lubrificante mineral em solução por grama de casca de arroz (P=5,0mL/g). 


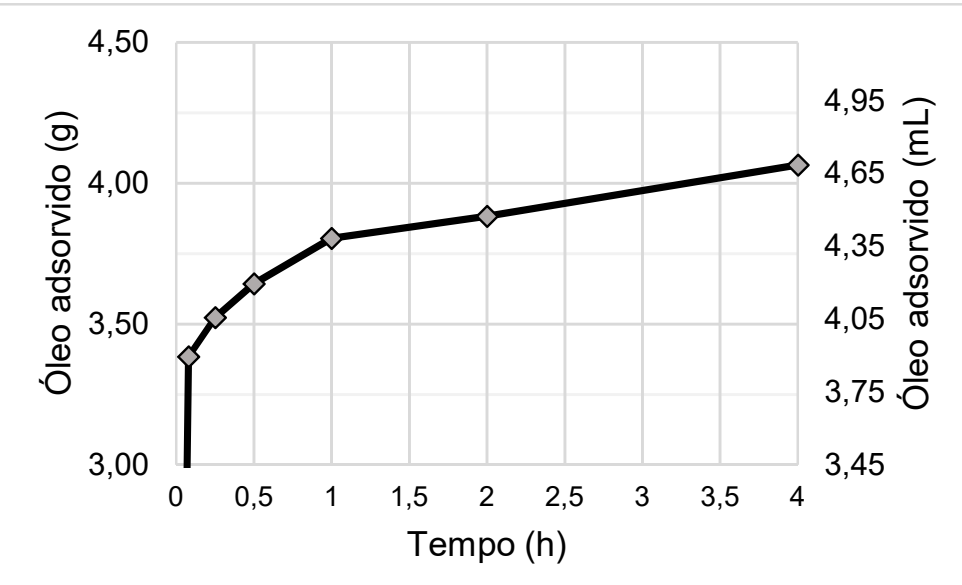

Figura 2: Adsorção de óleo lubrificante mineral em solução por grama de casca de arroz ( $\mathrm{P=2,0} \mathrm{mL} / \mathrm{g})$.

A Tabela 4 mostra uma comparação da eficiência de ambos os tratamentos estudados. O tratamento 1 possui uma maior eficiência de adsorção em $\mathrm{g}_{(\mathrm{OLM})} / \mathrm{g}_{(\mathrm{CA})}$, enquanto o tratamento 2 mostrou uma remoção muito maior do óleo total da solução, sendo o mais indicado.

Tabela 4: Comparativo dos resultados de ambos os tratamentos.

\begin{tabular}{|l|l|l|l|l|}
\hline Tempo de contato $(\mathrm{h})$ & Óleo adsorvido $(\mathrm{g})$ & \multicolumn{2}{l|}{ Óleo removido (\%) } \\
\hline 0,08 & Tratamento 1 & Tratamento 1 & Tratamento 1 & Tratamento 2 \\
\hline 0,25 & $1,54 \mathrm{~b}$ & $35,51 \mathrm{~b}$ & $35,51 \mathrm{~b}$ & $78,09 \mathrm{a}$ \\
\hline 0,50 & $1,70 \mathrm{~b}$ & $39,18 \mathrm{~b}$ & $39,18 \mathrm{~b}$ & $81,28 \mathrm{a}$ \\
\hline 1,00 & $1,73 \mathrm{~b}$ & $39,92 \mathrm{~b}$ & $39,92 \mathrm{~b}$ & $84,06 \mathrm{a}$ \\
\hline 2,00 & $1,80 \mathrm{~b}$ & $41,45 \mathrm{~b}$ & $41,45 \mathrm{~b}$ & $87,76 \mathrm{a}$ \\
\hline 4,00 & $1,89 \mathrm{~b}$ & $43,62 \mathrm{~b}$ & $43,62 \mathrm{~b}$ & $89,58 \mathrm{a}$ \\
\hline 0,08 & $1,91 \mathrm{~b}$ & $44,05 \mathrm{~b}$ & $44,05 \mathrm{~b}$ & $93,77 \mathrm{a}$ \\
\hline
\end{tabular}

Letras iguais na mesma linha não apresentam diferença significativa pelo teste de Tukey a 5\% de probabilidade.

\section{CONCLUSÕES}

A eficiência de adsorção de óleo lubrificante mineral pela casca de arroz variou de $36 \%$ a $94 \%$. 0 tempo de reação acontece de forma rápida, atingindo $80 \%$ de sua capacidade total nos primeiros 5 minutos de contato com o óleo e $90 \%$ da capacidade em 30 minutos. A proporção óleo/adsorvente de 2,00 mL/g demonstrou ser um método eficiente na remoção de óleo lubrificante mineral tendo $94 \%$ de óleo removido. O baixo valor da casca de arroz no mercado, sua disponibilidade na região sul do Rio Grande do Sul e sendo dispensável o tratamento prévio torna esse material uma alternativa interessante no tratamento de efluentes.

\section{REFERÊNCIAS}

ANNUNCIADO, T. R.; SYDENSTRICKER, T. H. D.; AMICO, S. C.. Experimental investigation of various vegetable fibers as sorbent materials for oil spills. Marine pollution bulletin, v.50, n.11, p.1340-1346, 2005. DOI:

http://doi.org/10.1016/j.marpolbul.2005.04.043

APHA. American Public Health Association. Standard Methods for the Examination of Water and Wastewater. Washington, 1999.
APHA. American Public Health Association. Standard Methods for the Examination of Water and Wastewater. Washington, 2005.

CONAMA. Conselho Nacional do Meio Ambiente. Resolução n.357: Dispõe sobre a classificação dos corpos de água e diretrizes ambientais para o seu enquadramento, bem como estabelece as condições e padrões de lançamento de efluentes, e dá outras providências. 2005.

DAI, J.; REN, F.; TAO, C. Y.. Adsorption of Cr (VI) and speciation of $\mathrm{Cr}(\mathrm{VI})$ and $\mathrm{Cr}$ (III) in aqueous solutions using 
chemically modified chitosan. International journal of environmental research and public health, v. 9, n. 5, p. 1757-1770, 2012. DOI: http://doi.org/10.3390/ijerph9051757

GMP. Grupo de Monitoramento Permanente. Diretrizes para o licenciamento ambiental de atividades ligadas aos óleos lubrificantes usados ou contaminados. 2005.

HEMALATHA, R.; CHITRA, R.; XAVIER, R. R.. Sudha PN: Synthesizing and characterization of chitosan graft co polymer: adsorption studies for $\mathrm{Cu}$ (II) and $\mathrm{Cr}(\mathrm{VI})$.

International Journal of Environmental Sciences, v.2, n.2, p.805-828, 2013. DOI:

http://doi.org/0.6088/ijes.00202020041

MAGALHÃES, M. A.; MONACO, P. A. V. L.; MATOS, A. T.. Uso de filtros orgânicos na remoção de óleos e graxas presentes na água residuária de suinocultura. Engenharia na Agricultura, v.21, n.4, p.387-395, 2013.

MOREIRA, D. R.. Desenvolvimento de adsorventes naturais para tratamento de efluentes de galvanoplastia.

Dissertação (Mestrado) - Pontifícia Universidade Católica do Rio Grande do Sul, 2010.

NASCIMENTO, R. F.; LIMA, A. C. A.; VIDAL, C. B.; QUADROS MELO, D.; RAULINO, G. S. C.. Adsorção: aspectos teóricos e aplicações ambientais. Biblioteca de Ciências e Tecnologia, 2014.

NETO, L. A. B.. Uso de casca de arroz para adsorção de óleo lubrificante mineral. Monografia (Graduação em Engenharia Ambiental e Sanitária) - Universidade Federal de Pelotas, Pelotas, 2017.

PENHA, R. S.; SANTOS, C. C.; CARDOSO, J. J.; SILVA, H. A.; SANTANA, S. A.; BEZERRA, C. W. B.. Casca de arroz Quimicamente Tratada como Adsorvente de Baixo Custo para a Remoção de Íons Metálicos ( $\mathrm{Co} 2+$ and $\mathrm{Ni2}+)$. Revista Virtual de Química, v.8, n.3, p.588-604, 2016.

DOI: http://doi.org/10.5935/1984-6835.20160045

RIBEIRO, T. H.; SMITH, R. W.; RUBIO, J.. Sorption of oils by the nonliving biomass of a Salvinia sp. Environmental Science and Technology, v.34, n.24, p.5201-5205, 2000. DOI: http://doi.org/10.1021/es991139g

SIGNINI, R.; ARRUDA, A. F. O.. Uso de quitosana e derivados como adsorvente de cromo. Processos Químicos, v.8, p.2937,2010

ZHANG, Y.; GHALY, A. E.; LI, B.. Physical properties of rice residues as affected by variety and climatic and cultivation conditions in three continents. American Journal of Applied Sciences, v.9, n.11, p.1757-1768, 2012.

A CBPC - Companhia Brasileira de Produção Científica (CNPJ: 11.221.422/0001-03) detém os direitos materiais desta publicação. Os direitos referem-se à publicação do trabalho em qualquer parte do mundo, incluindo os direitos às renovações, expansões e disseminações da contribuição, bem como outros direitos subsidiários. Todos os trabalhos publicados eletronicamente poderão posteriormente ser publicados em coletâneas impressas sob coordenação da Sustenere Publishing, da Companhia Brasileira de Produção Científica e seus parceiros autorizados. Os (as) autores (as) preservam os direitos autorais, mas não têm permissão para a publicação da contribuição em outro meio, impresso ou digital, em português ou em tradução. 